\title{
Methods of design a multiport measurements
}

\author{
Vladimir Nechaev ${ }^{1, *}$, Oleg Kravchenko ${ }^{1}$, and Vladimir Ulyanov ${ }^{1}$ \\ ${ }^{1}$ RPC Micran, 634041, 51d Kirova Avenue, Tomsk, Russia
}

\begin{abstract}
The main implementation options for multiport RF and microwave measurements using n-port vector network analyzers, as well as switching measuring expansion units, are considered. A switching measuring unit and a port expander unit manufactured are presented by RPC Micran.
\end{abstract}

\section{Introduction}

With the development of the electronic industry, there is a need for testing multiport devices - both for testing multiple devices at the same time, and for testing a single multiport device. In recent years, multiport vector network analyzers (VNAs), or VNAs working in conjunction with port expansion units have become one of the most important measuring tools for characterizing high-frequency (RF) and microwave components and devices for various purposes $[1,2]$. Devices of this type are used both at the stage of development and scientific research, and during testing in the industrial production of equipment. Modern requirements for the quality of radio-electronic devices determine the need to improve performance and achieve high accuracy of measurements of research tools for multiport microwave devices [3].

\section{Main part}

Multiport VNAs generally have a similar architecture, with the exception of the use of one or two signal sources for sensing the device under test (DUT).

The second internal signal source provides an additional test signal (with fixed parameters or in the swing mode of one of them), for example, to measure the parameters of the intermodulation distortion of amplifiers in the two-tone input mode or the local oscillator signal when measuring the parameters of mixers and frequency converters. The use of a multi-channel receiver ( 5 or 8 channels) with simultaneous sampling by channels allows phase measurements on antenna arrays. These solutions make it possible to carry out multi-signal measurements using one VNA, which significantly reduces the time of testing devices and the cost due to the fact that the cost of a 4-port VNA is much less than the cost of a test system consisting of several measuring instruments. This solution does not allow measurements of the matrix of S-parameters of devices with five and a large number of ports, which in turn imposes significant restrictions on the speed and total measurement time.

${ }^{*}$ Corresponding author: nechaev.vg@micran.ru 
Typical schemes of 4-port VNAs are presented in Figure 1 [4].
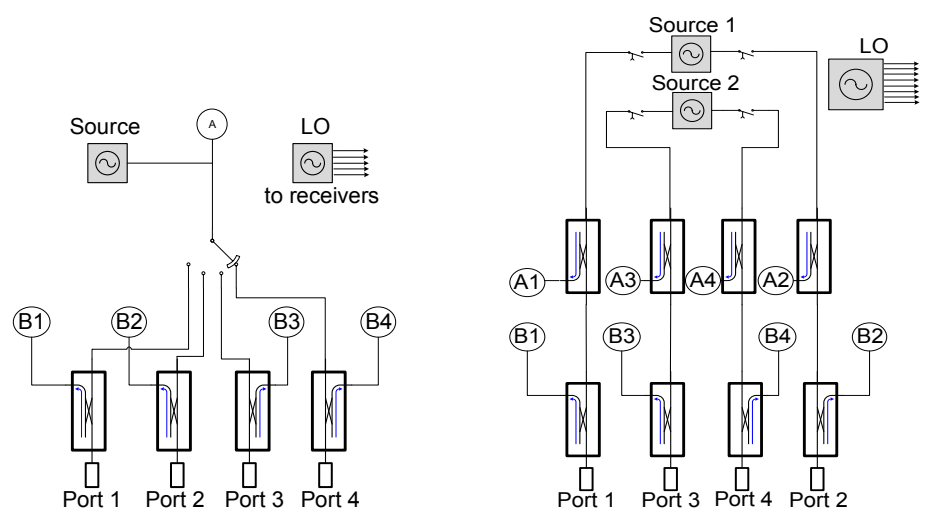

Fig. 1. Typical schemes of 4-port VNA.

Recently, multiport measuring switching units or port extensions have gained great popularity, which make it possible to measure the parameters of multiport devices. Measuring units of this type are designed for joint use with 2- and 4-port VNAs and have a different number of measuring ports, as well as different frequency ranges. Structurally, they can use electromechanical or solid-state switches and can be of two types: expanding and switching.

Port switching units are connected directly to the VNA measuring ports, allowing the use of receivers and directional couplers of each VNA measuring port for measurements on several ports of the external measuring unit. The company RPC Micran produces port switching units of this type, which allow precise measurements of the electrical parameters of radio circuits and devices in a wide dynamic range. Port switching units differ from each other by the upper limit of the operating frequency range $(13.5 \mathrm{GHz}, 20 \mathrm{GHz}$, and $26.5 \mathrm{GHz}$ ), as well as the number of measuring ports equal to 16 or 32 .

The solution includes electromechanical switches SP3T and SP5T. The use of switches of this type provides minimal loss per passage and a high level of isolation, which in turn allows measurements of noise parameters of devices in contrast to existing analogues (Figure 2).
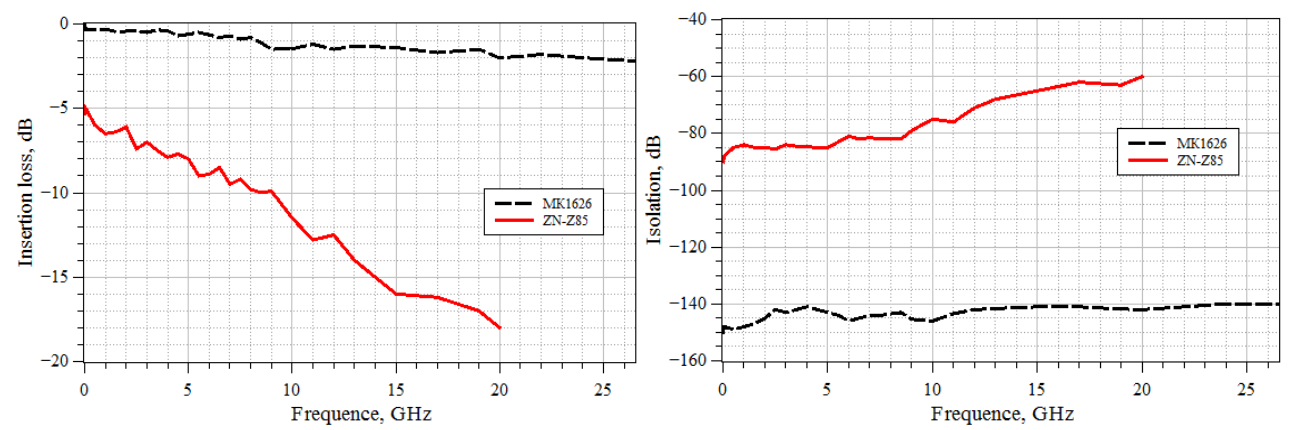

Fig. 2. Comparison of the main parameters of port switching units MK1626 (RPC Micran) and ZN-Z85 (Rodhe \& Schwarz).

The circuit of the port switching unit is shown in Figure 3.

Foreign analogues are built using solid-state switches, which provides a high measurement speed, but the choice of switches of this type imposes restrictions on the quality of the metrological characteristics of the measuring system on the RF (Table 1). 


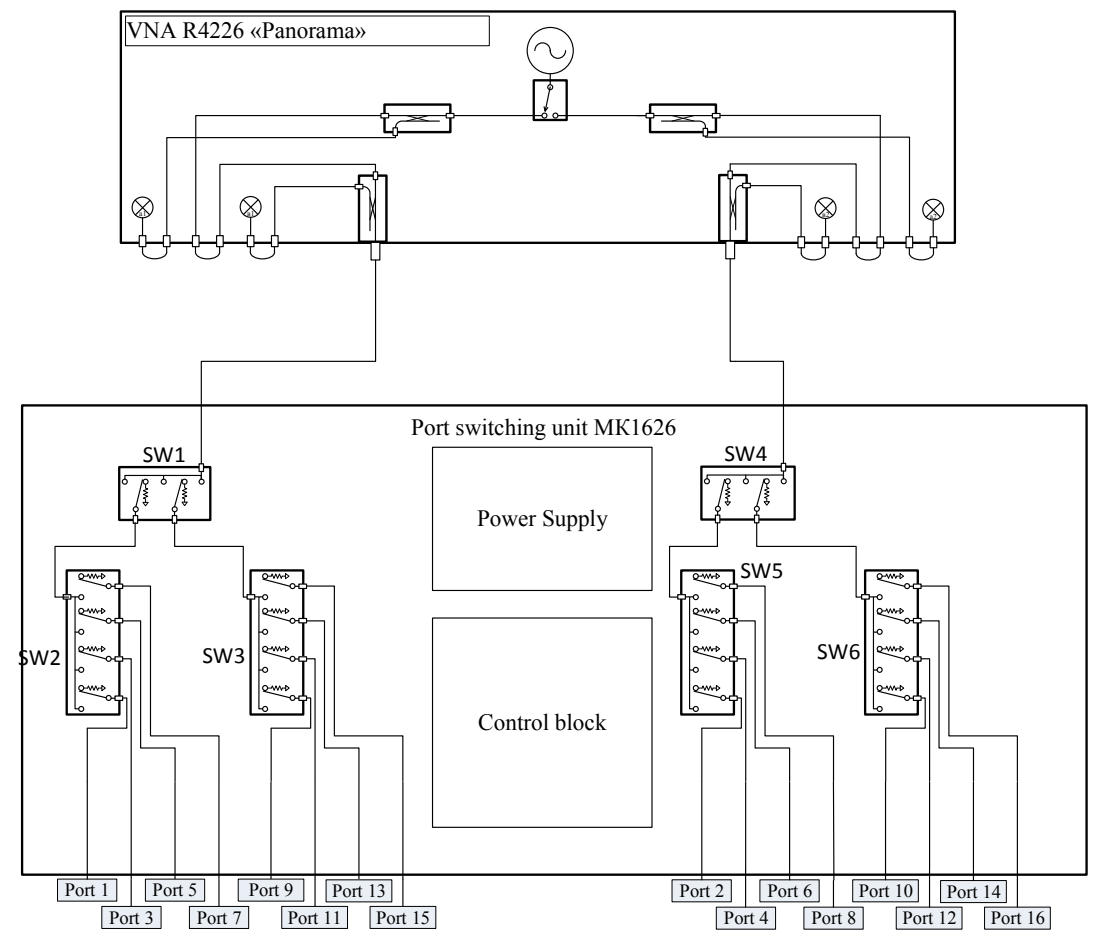

Fig. 3. Scheme of the port switching unit MK1626 working in conjunction with the VNA R42 «Panorama» series.

The disadvantages of such devices include the fact that they only measure the parameters of the path included between sets of switches, and the parameters of the paths where the input and output are closed on the same set of switches cannot be measured, which leads to limitations when complete cross-sectional measurements [5].

Table 1. Comparison of characteristics of port switching units.

\begin{tabular}{|c|c|c|c|c|c|}
\hline \multirow[b]{3}{*}{ Characteristic } & \multicolumn{5}{|c|}{ Manufacturer } \\
\hline & \multicolumn{3}{|c|}{ RPC Micran } & \multicolumn{2}{|c|}{ Rohde \& Schwarz } \\
\hline & MK1613 & MK1626 & $\begin{array}{c}\text { Hardware } \\
\text { and } \\
\text { software } \\
\text { Complex } \\
\text { K2M-102 }\end{array}$ & $\mathrm{ZN}-\mathrm{Z} 85$ & ZN-Z84 \\
\hline Number of ports & \multicolumn{2}{|c|}{16} & 32 & 12 & 24 \\
\hline $\begin{array}{c}\text { Operating } \\
\text { frequency range }\end{array}$ & $\begin{array}{c}300 \mathrm{kHz} \\
\text { to } 13,5 \mathrm{GHz}\end{array}$ & $\begin{array}{c}10 \mathrm{MHz} \\
\text { to } 26,5 \mathrm{GHz}\end{array}$ & $\begin{array}{l}10 \mathrm{MHz} \\
\text { to } 20 \mathrm{GHz}\end{array}$ & $\begin{array}{l}10 \mathrm{MHz} \\
\text { to } 20 \mathrm{GHz}\end{array}$ & $\begin{array}{l}10 \mathrm{MHz} \\
\text { to } 8,5 \mathrm{GHz}\end{array}$ \\
\hline $\begin{array}{l}\text { Loss, at the worst } \\
\text { point, } \mathrm{dB}, \\
\text { no more }\end{array}$ & 1,5 & 2,2 & 1,5 & 18 & 12 \\
\hline VSWR, no more & 1,3 & 1,7 & 1,2 & - & - \\
\hline $\begin{array}{c}\text { Isolation, } \mathrm{dB}, \\
\text { not less }\end{array}$ & 140 & 140 & 140 & 60 & 70 \\
\hline $\begin{array}{l}\text { Switching time, } \\
\text { ms, no more }\end{array}$ & \multicolumn{3}{|c|}{15} & 2 & 2 \\
\hline
\end{tabular}


The RPC Micran linear control and measuring equipment has port expansion units M813 and M826, covered with operating frequencies from $300 \mathrm{kHz}$ to $13.5 \mathrm{GHz}$ and from $10 \mathrm{MHz}$ to $26.5 \mathrm{GHz}$, as well as with parameters 4 and 8 of the measuring signals, respectively (Figure 4). Data has high matched ports, S-parameter values, wave values and their relationships (Figure 5).

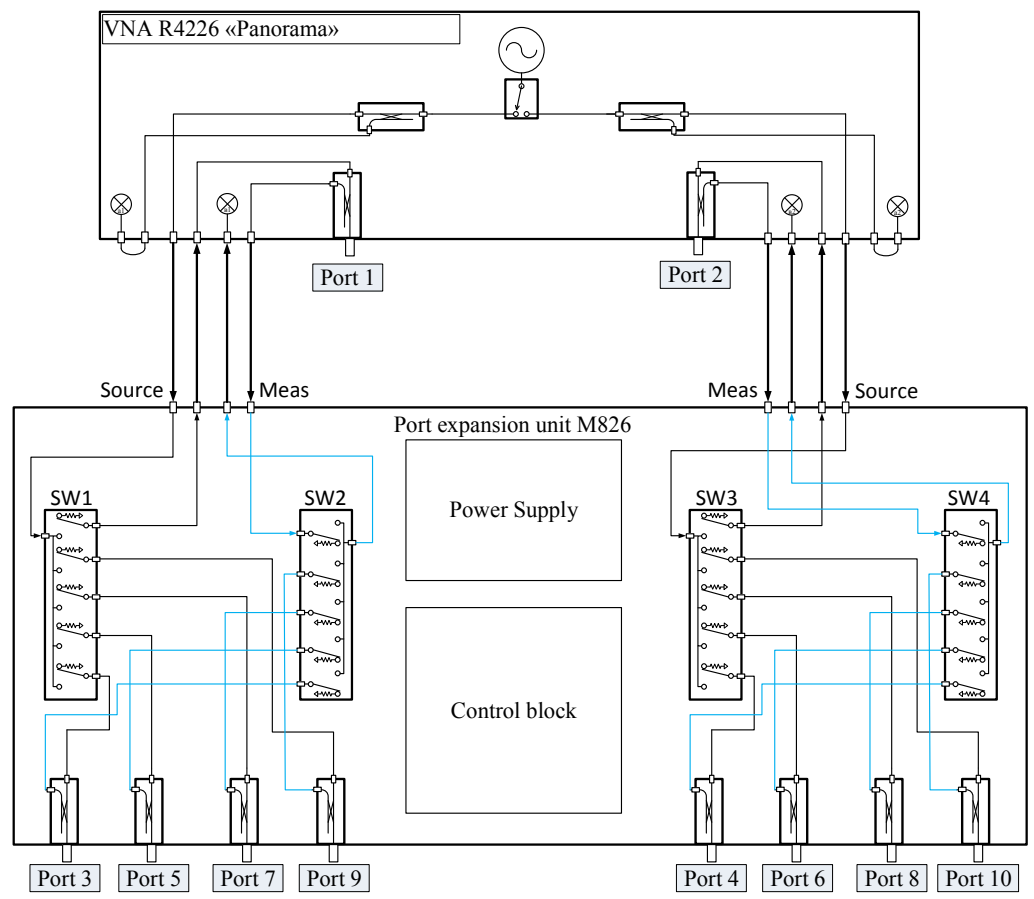

Fig. 4. Scheme of the port expansion unit M826 working in conjunction with the VNA R42 «Panorama» series.

A distinctive feature of this solution is that the port expansion unit is connected directly to the path of the external jumpers of the signal source and VNA receiver circuits to the taps of the measuring port. The presence of a directional coupler for each measuring port ensures stability and high metrological characteristics during RF and microwave measurements, and expands the switching matrix of the signal source used by the VNA, creating a larger number of outputs switched by it. With this implementation, the main ports of the VNA remain free for measurements, in contrast to the previously described switching method.

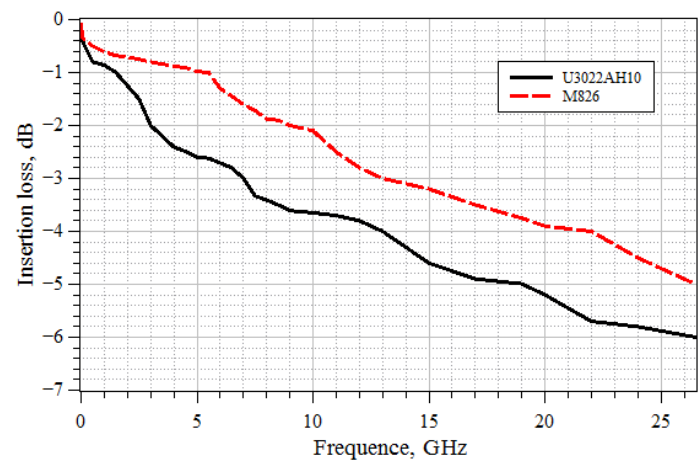

Fig. 5. Comparison of parameters of port expansion units M826 (RPC Micran) and U3022AH10 (Keysight Technologies). 
Since switching is carried out before measuring directional couplers, the metrological characteristics of this solution are significantly higher compared to port switching units. It should also be noted that in this case, the path loss caused by the switches does not affect the stability of the measurements, due to their compensation at the calibration stage of this system. The main parameters of devices of this type are presented in table 2 .

Table 2. Comparison of characteristics of port switching units.

\begin{tabular}{|c|c|c|c|c|}
\hline \multirow{3}{*}{ Characteristic } & \multicolumn{4}{|c|}{ Manufacturer } \\
\hline & \multicolumn{2}{|c|}{ RPC Micran } & \multicolumn{2}{|c|}{ Keysight Technologies } \\
\hline & M813 & M826 & U3042AM04 & U3022AH10 \\
\hline Number of ports & \multicolumn{2}{|c|}{4 or 8} & 4 & 10 \\
\hline $\begin{array}{c}\text { Operating } \\
\text { frequency range }\end{array}$ & $\begin{array}{c}300 \mathrm{kHz} \\
\text { to } 13,5 \mathrm{GHz}\end{array}$ & $\begin{array}{c}10 \mathrm{MHz} \\
\text { to } 26,5 \mathrm{GHz}\end{array}$ & $\begin{array}{c}10 \mathrm{MHz} \\
\text { to } 26,5 \mathrm{GHz}\end{array}$ & $\begin{array}{c}10 \mathrm{MHz} \\
\text { to } 26,5 \mathrm{GHz}\end{array}$ \\
\hline $\begin{array}{l}\text { Loss, at the worst } \\
\text { point, dB, no more }\end{array}$ & 2,8 & 5 & 5 & 6 \\
\hline VSWR, no more & 1,3 & 1,8 & - & - \\
\hline $\begin{array}{c}\text { Isolation, } \mathrm{dB} \text {, not } \\
\text { less }\end{array}$ & \multicolumn{2}{|c|}{140} & - & - \\
\hline $\begin{array}{l}\text { Switching time, } \\
\text { ms, no more }\end{array}$ & \multicolumn{2}{|c|}{15} & \multicolumn{2}{|c|}{15} \\
\hline
\end{tabular}

When operating the presented multi-port measuring systems, it is possible to carry out simplified calibration, which can significantly accelerate the total time of measurements. In this case, there is no need to carry out traditional calibration methods, which require measurements of the parameters of each of the signal paths. To calibrate reflection ports, it is sufficient to calibrate one port, and calculate the remaining ports using QSOLT technology, after calibration for passage [5]. With this approach, it is simple enough to provide a complete multi-port calibration using an electronic calibrator or a set of calibration measures. Notably that it is possible to calibrate and measure only the necessary part of the matrix of S-parameters. This will slightly impair accuracy, but significantly increase the performance of the device. It is also possible to perform a full calibration, and during the measurement process to switch between full and simplified correction.

Figures 6, 7 show an example of a measurement scheme for a power divider using a port expansion unit working in conjunction with the VNA R42 «Panorama» series and an example of measuring a five-port device.

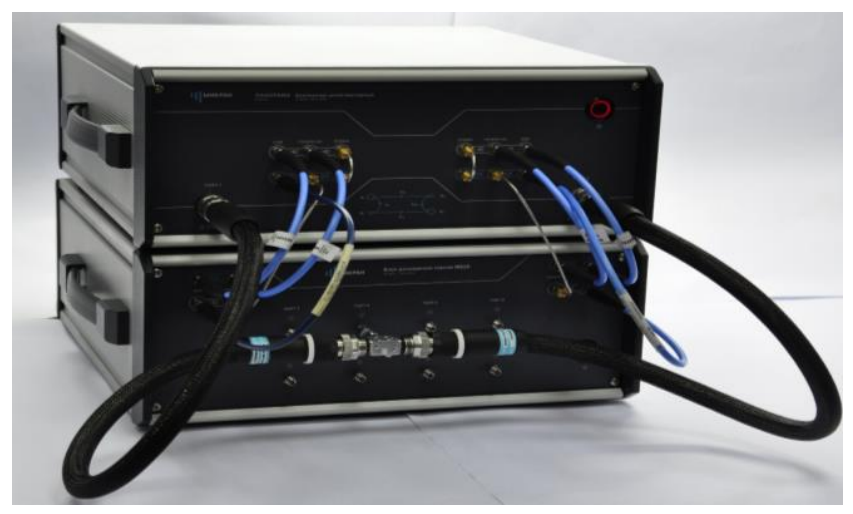

Fig. 6. An example of a power divider measurement circuit. 


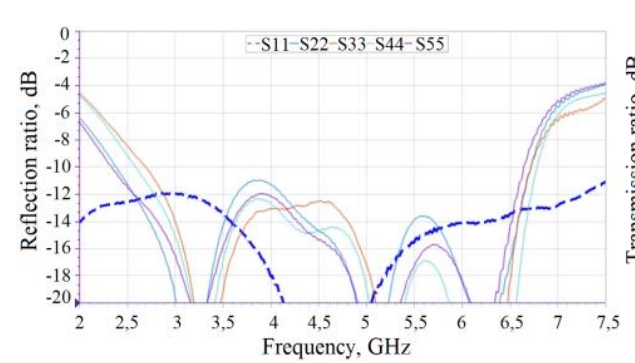

a)

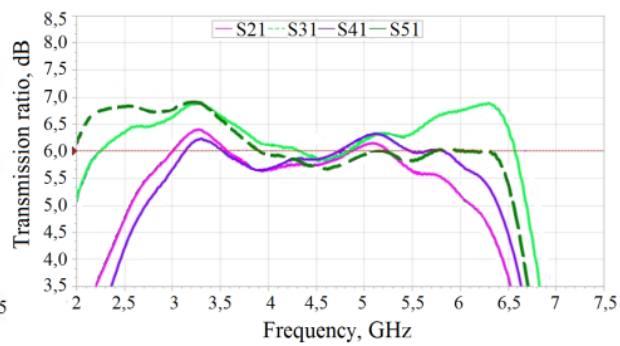

b)

Fig. 7. An example of a five-port device measurement: a) reflection ratio; b) transmission ratio.

\section{Conclusion}

The basic concepts of providing multi-port measurements are presented. The advantages and disadvantages of a particular measurement method, as well as the difficulties of implementing multi-port circuit measuring systems are highlighted.

To ensure multi-signal measurements using a single VNA, a series of switching measuring units and port expander units is presented, developed by RPC Micran. These devices can be used both in development and in testing dividers and adders, switches, complex antenna systems and other multiport devices without loss of time due to matrix control. The proposed solutions in terms of their characteristics, including low insertion loss, high isolation between ports, a wide dynamic range, as well as repeatability of characteristics are not inferior to analogues of well-known foreign manufacturers, and in some moments surpass them.

\section{References}

1. Joel P. Dunsmore. Handbook of Microwave Component Measurements: With Advanced VNA Techniques, By John Wiley \& Sons, Ltd., 66-70 p., (2012)

2. Agilent AN 1287-1. Understanding the Fundamental Principles of Vector Network Analysis. Application Note, 2-4 p., (2000)

3. Martin S. 4-port VNA versus 2 port VNA: A comparison of methods for measuring the $S$ parameters of a directional coupler $/ / 4^{\text {th }}$ European ANAMET Seminar METAS, Bern, Switzerland, 1-16 p., (2015)

4. Hibel M. Fundamentals of vector circuit analysis. - Per. from English CM. Smolsky; under the editorship of W. Philip. - M.: Publishing house MPEI, 26-28 p. (2009)

5. Joel P. Dunsmore. Handbook of the engineer. Measurement of parameters of microwave devices using advanced techniques of vector circuit analysis. - Translation from English E.Yu. Kharitonova, E.V. Andronova, A.S. Bondarenko. - Moscow: Technosphere, 125, 197 p. (2018) 